\title{
Monitoring Soil Nitrate Nitrogen Based on Hyperspectral Data in the Apple Orchards
}

\author{
Yu Wei', Xicun Zhu' ${ }^{1,2}$, Cheng Li' ${ }^{1}$, Lizhen Cheng1, Ling Wang', Gengxing Zhao1, Yuanmao Jiang ${ }^{3}$ \\ ${ }^{1}$ College of Resources and Environment, Shandong Agricultural University, Tai'an, China \\ ${ }^{2}$ Key Laboratory of Agricultural Ecology and Environment, Shandong Agricultural University, Tai'an, China \\ ${ }^{3}$ College of Horticulture Science and Engineering, Shandong Agricultural University, Tai'an, China \\ Email: wy18763890707@163.com
}

How to cite this paper: Wei, Y., Zhu, X.C., Li, C., Cheng, L.Z., Wang, L., Zhao, G.X. and Jiang, Y.M. (2017) Monitoring Soil Nitrate Nitrogen Based on Hyperspectral Data in the Apple Orchards. Agricultural Sciences, 8, 21-32.

http://dx.doi.org/10.4236/as.2017.81002

Received: December 7, 2016

Accepted: January 2, 2017

Published: January 5, 2017

Copyright (C) 2017 by authors and Scientific Research Publishing Inc. This work is licensed under the Creative Commons Attribution International License (CC BY 4.0).

http://creativecommons.org/licenses/by/4.0/

\begin{abstract}
This paper is aimed to monitor the soil nitrate nitrogen content in the apple orchards rapidly, accurately and in real time by making full use of the effective information of soil spectra. The 96 air-dried soil samples of the apple orchards in Qixia county, Yantai city, Shandong province were used as the data source. Spectral measurements of soil samples were carried out by ASD Fieldspec 3 in the darkroom, and the content of the soil nitrate nitrogen was determined by chemical method. Then the hyperspectral reflectance of soil samples were preprocessed by Multivariate Scatter Correction (MSC) and First Derivative (FD), the correlation analysis was carried out with the soil nitrate nitrogen content. The sensitive wavelength of soil nitrate nitrogen was screened. Finally, the Support Vector Machine (SVM) model for the soil nitrate nitrogen content was established. The results showed that the selected sensitive wavelength were $617 \mathrm{~nm}, 760 \mathrm{~nm}, 1239 \mathrm{~nm}, 1442 \mathrm{~nm}, 1535 \mathrm{~nm}, 1695 \mathrm{~nm}, 1776$ $\mathrm{nm}, 1907 \mathrm{~nm}$ and $2088 \mathrm{~nm}$. Hyperspectral monitoring model was established by SVM, in which the prediction set $\mathrm{R}^{2}$ was 0.959 , RMSE was 0.281 , RPD was 3.835; the correction set $\mathrm{R}^{2}$ was 0.822 , RMSE was 0.392 , RPD was 2.037 . The SVM model could be used to monitor the soil nitrate content accurately.
\end{abstract}

\section{Keywords}

Hyperspectrum, Nitrate Nitrogen Content, Support Vector Machine, Sensitive Wavelength

\section{Introduction}

Soilnitrate nitrogen is the best nitrogen source for crops; it has non-volatility and can be directly absorbed by plants. It can promote the absorption of potassium, calcium, magnesium and other cations, and limit the absorption of harmful sub- 
stances. It plays an important role in the nutrient absorption process of crops. In the north of China, the soil is mainly dominated by nitrate nitrogen, and its content reflects the short-term of the soil nitrogen supply directly. Therefore, the real-time monitoring of the soil nitrate nitrogen content has important practical significance in crop growth status, crop yield and soil pollution prevention. The traditional chemistry method of soil nitrate nitrogen-ultraviolet spectrophotometry, which has high measuring precision, is time-consuming and laboriousand is difficult to analyze the results in a timely manner. In recent years, the emerging hyperspectral remote sensing technology has the advantages of high resolution, strong band continuity and large spectral information, which provides technical support for rapid, non-destructive and accurate monitoring of the soil nitrate nitrogen content [1].

Using hyperspectral technology combined with different pretreatment methods and modeling methods, the soil nitrogen content (mainly focused on soil total nitrogen) was monitored by domestic and foreign scholars. Yet monitoring soil nitrate nitrogen content is rare. In early 21st century, Chang et al. [2] used the near-infrared spectroscopy modeling and analysis technology to monitor the total nitrogen content of 744 soil samples from the United States, with an accuracy of 0.85 and a good estimate of total nitrogen. Confalonieri et al. [3] obtained near-infrared spectroscopy data of different soil types using Fourier transform near-infrared spectrometer, then the content of soil component including the nitrogen content was well predicted and analyzed. Lee et al. [4] used PLSR and SMLR to model 165 surface soil samples and 697 soil profile samples from the United States corn growing areas. The results indicated that the characteristic band of soil nitrogen was about $510 \mathrm{~nm}$, and the content of total nitrogen in soil was successfully predicted. Genot et al. [5] used the improved PLSR model to establish the local model of the soil total nitrogen in Wallonia of Belgium with an accuracy of more than 0.9 and the model had a good prediction accuracy. The content of total nitrogen in different soil types was predicted by the domestic scholars. YuJianfei et al. [6] estimated the soil total nitrogen content using the first derivative pretreatment method combined with the partial least-squares regression model. The model accuracy was 0.88. Lu Yanli et al. [7] estimated the total nitrogen content in black soil using the first derivative of the logarithm of soil reflectance and the normalized spectral index and $\mathrm{R}^{2}$ reached $0.863,0.829$ respectively. Zhang Jianjuan et al. [8] studied the quantitative relationship between total nitrogen and hyperspectral reflectance of five types of soils in central and eastern China. Based on this, the partial least squares (PLS) model, BP neural network (BPNN) model were established. The models were of high precision and could be used to estimate the soil total nitrogen content. Different soil hyperspectral data pretreatment methods and different modeling methods will affect the prediction accuracy of the model. Peng Jie et al. [9] studied the four main types of cultivated soils in Hunan Province, analyzed the correlations between different spectral indices and the soil total nitrogen content and established the linear regression model and the stepwise multiple regression model. 
The results showed that the accuracy of the multiple stepwise regression model established by (1/log)' was the highest. Yang Chao et al. [10] carried out different pretreatments of soil near-infrared spectral data and established the PLSR model to monitor soil total nitrogen content. The results showed that different pretreatment methods would greatly affect the accuracy of the model and the smoothing +MSC+OSC method was the best. Viscarra Rossel et al. [11] applied the discrete wavelet transform to the spectra of 876 soil samples in Australia. The models of stochastic forest (RF), support vector machine (SVM) and artificial neural network (ANN) had been established, and the results showed that the SVM model performed the best. Ji Wenjun et al. [12] predicted the SOM content of 441 paddy soils in Zhejiang Province using PLSR, RF, SVM, ANN and PLSRANN models, the conclusion also showed that the SVM model had the best effect.

The above studies showed that it was feasible to monitor the soil nitrogen content using hyperspectral technology. Previous studies mainly focused on the quantitative relationship between soil total nitrogen content and hyperspectral reflectance, but monitoring of the soil nitrate nitrogen content is rarely reported. The main reason is that the content of soil nitrate nitrogen is lower than that of total nitrogen, so it is difficult to monitor the soil nitrate nitrogen by using hyperspectral technique. Based on the correlation analysis between hyperspectral data of the apple orchards soils in Qixia and nitrate nitrogen content measured by chemical experiments, the Support Vector Machine (SVM) model was established, in order to provide theoretical basis and technical support for monitoring the soil nitrate nitrogen content by using hyperspectral techniques.

\section{Material and Methods}

\subsection{Study Area}

The study area was located in Qixia City $\left(120^{\circ} 33^{\prime}-121^{\circ} 15^{\prime}, 37^{\circ} 05^{\prime}-37^{\circ} 32^{\prime}\right)$, which is situated in the center of Jiaodong Peninsula (Figure 1). The total area is $201,600 \mathrm{hm}^{2}$, and the area of orchards is $43,300 \mathrm{hm}^{2}$. Qixia City has four distinct seasons and plenty of sunshine. Its climate is warm and semi-humid monsoon. The annual average temperature is $11.3^{\circ} \mathrm{C}$, the annual average rainfall is about $650 \mathrm{~mm}$, the frost-free period is $207 \mathrm{~d}$, and the total sunshine duration is $2690 \mathrm{~h}$. Qixia belongs to mountain hilly terrain. The parent material is mostly acid rock, granite, gneiss. The soil type is mainly brown soil.

\subsection{Soil Samples Collection and Preparation}

The samples were collected from 32 orchards in 3 streets and 12 townships in Qixia city (Figure 1). The sampling time was 20 - 23 October 2010 and the sampling depth was $0-20 \mathrm{~cm}$. Three trees were selected randomly from each orchard, and each tree was taken as a sampling point. Soil samples were collected in the four directions vertically from the east to the west of the crown edge of the selected fruit tree, and then mixed. A total of 96 soil samples were obtained. The soil samples were naturally air-dried, crushed, decontaminated, ground, sieved 


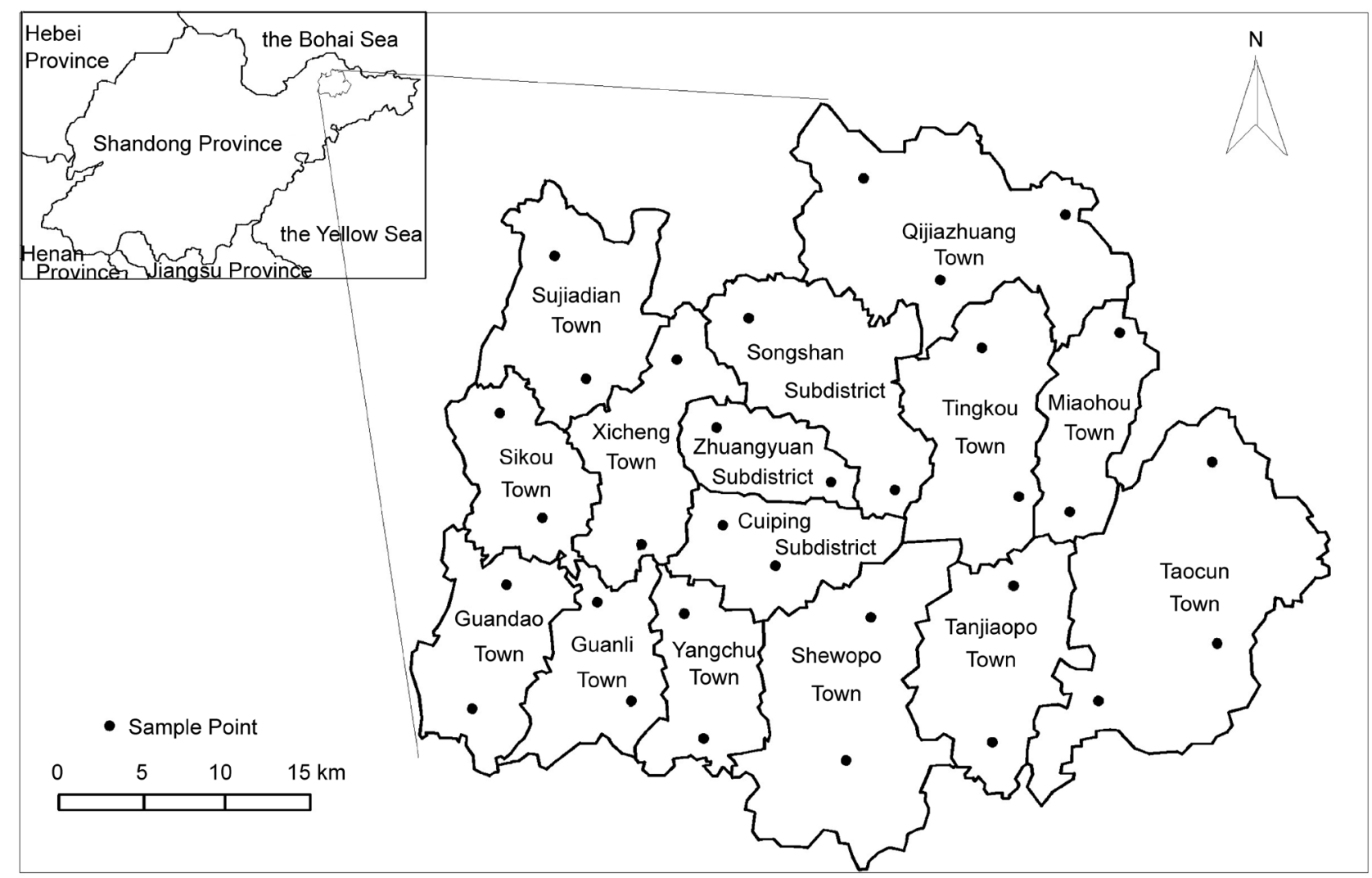

Figure 1. The geographical location of Qixia and distribution of sample points.

through a $1 \mathrm{~mm}$ sieve and mixed thoroughly. $100 \mathrm{~g}$ soil samples were taken by quartile method, respectively [13], into a dish $(2 \mathrm{~cm})$ for the measurement of soil nitrate nitrogen content and soil spectrum. The collected samples were randomly divided into two groups. The prediction set (72) was used for modeling, and the calibration set (24) was used for model checking.

\subsection{Soil Spectral Date and Nitrate Nitrogen Content Determination}

\subsubsection{Soil Spectral Date Measurements}

Soil spectral data were measured by ASD Fieldspec 3. The spectral range is $350 \sim$ $2500 \mathrm{~nm}$. The sampling interval was $1.4 \mathrm{~nm}$ and the spectral resolution was 3.5 $\mathrm{nm}$ during $350 \sim 1000 \mathrm{~nm}$; the sampling interval was $2 \mathrm{~nm}$ and the spectral resolution was $10 \mathrm{~nm}$ during $1000 \sim 2500 \mathrm{~nm}$. When the spectrum was output, the resampling interval was $1 \mathrm{~nm}$ and the total number of output bands was 2151 [14]. Spectral measurements were carried out in a dark room. The sample dishes were filled with soil samples and placed on black rubber mats with a reflectivity of 0 approximately and a thickness of $3 \mathrm{~cm}$. The light source used a $50 \mathrm{w}$ halogen lamp, the probe's field of view was $25^{\circ}$, the light source incidence angle was $45^{\circ}$, the distance of the probe to the soil surface was $15 \mathrm{~cm}$ and the light source to the soil center distance was $30 \mathrm{~cm}$. During the measurement, the standard white plate was calibrated every 20 minutes, the sample was rotated three times and rotated about $90^{\circ}$. The soil sample curve was obtained in four directions. Each 
soil sample was measured 10 times and the arithmetic mean was taken as the reflection spectrum data of the soil sample [15]. The edge region (350 - $399 \mathrm{~nm}$ and $2451-2500 \mathrm{~nm}$ ) with larger spectral noise was removed, and only the band (400- $2450 \mathrm{~nm}$ ) was reserved for the follow-up study.

\subsubsection{Soil Nitrate Nitrogen Content Analyses}

After the data collection was completed, the content of soil nitrate nitrogen was determined by ultraviolet spectrophotometry [16]. $10 \mathrm{~g}$ air-dried soil samples were accurately weighed and placed in a $100 \mathrm{ml}$ stoppered Erlenmeyer flaskadding with $0.1 \mathrm{~g}$ of $\mathrm{CaSO}_{4}$ and $50 \mathrm{ml}$ of distilled water. In the $(25 \pm 1)^{\circ} \mathrm{C}$ conditions, the flask was shaken on the shaker for $10 \mathrm{~min}$ at a rate of $150 \mathrm{r} / \mathrm{min}$ and placed $10 \mathrm{~min}$. Then the supernatant was filtered with dry filter paper. $10 \mathrm{~mL}$ of the filtrate was pipetted into a $25 \mathrm{~mL}$ cuvette. The absorbance was measured at $220 \mathrm{~nm}$ and $275 \mathrm{~nm}$ respectively by the UV-2102 ultraviolet-visible spectrophotometer. The mass fraction of nitratenitrogen in each soil sample were calculated according to the calibration standard curve (correlation coefficient was 0.995). The results of the determination of the nitrate nitrogen content in 96 soil samples were shown in Table 1.

\subsection{Soil Spectral Date Preprocessing}

In order to reduce the spectral data affected by laboratory optical field variation and sample in homogeneity, spectral data were analyzed by Multivariate Scatter Correction (MSC) combined with First Derivative (FD), Savitzky-Golay Smoothing combined with First Derivative(FD), and Savitzky-Golay smoothing, Multiple Scattering Correction combined with First Derivative (FD) processing. Through the comparative analysis of the late prediction results, we can see that the multispectral correction plus First Derivative (FD) is the best. It is showed that MSC combined with FD transform method had the best effect.

\subsubsection{Multivariate Scatter Correction (MSC)}

MSC was proposed by Martens et al. [17], is a data processing method which is commonly used in a multi-band calibration modeling at this stage. MSC is mainly used to eliminate scattering effects caused by the uneven distribution of particles and particle size and eliminate the phenomenon of baseline shift and migration caused by scattering of near-infrared spectroscopy, thereby enhancing the Signal to Noise Ratio of the original absorbance spectrum and enhancing the spectral absorption information associated with component content [18].

The algorithm of MSC was as follows [19]:

1) Calculate the average spectrum of the calibration set samples $x(1 \times \mathrm{m})$ (ideal spectrum);

Table 1. Statistics of nitrate nitrogen content of soil samples.

\begin{tabular}{ccccc}
\hline $\begin{array}{c}\text { Number of } \\
\text { samples }\end{array}$ & Mean $/ \mathrm{mg} \cdot \mathrm{kg}^{-1}$ & $\begin{array}{c}\text { Standard deviation/ } \\
\mathrm{mg} \cdot \mathrm{kg}^{-1}\end{array}$ & $\begin{array}{c}\text { Maximum } \\
/ \mathrm{mg} \cdot \mathrm{kg}^{-1}\end{array}$ & $\begin{array}{c}\text { Minimum } \\
/ \mathrm{mg}^{-\mathrm{kg}^{-1}}\end{array}$ \\
\hline 96 & 13.938 & 11.312 & 52.607 & 1.321 \\
\hline
\end{tabular}


2) Linear regression of $x i$ and $\bar{x}, x_{i}=l a_{i}+x b_{i}$, find $a_{i}$ and $b_{i}$;

3) $\mathrm{x}_{\mathrm{i} . \mathrm{MSC}}=\left(\mathrm{x}_{\mathrm{i}}-\mathrm{la}_{\mathrm{i}}\right) / \mathrm{b}_{\mathrm{i}}$

(Among, $\overline{\mathrm{x}}$ was the average spectrum of the calibration set samples; $\mathrm{x}_{\mathrm{i}}$ was the average value of the $i$ th sample spectrum; $x_{i . M S C}$ was the mean value of the ith sample spectrum after MSC treatment; $\mathrm{i}=1,2, \ldots, n, n$ was the number of the calibration set samples; 1 was the unit vector of $1 \times \mathrm{m}$; $\mathrm{m}$ was the number of wavelength points.)

\subsubsection{First Derivative (FD)}

Differential transformation can eliminate the effect of baseline drift and high frequency noise and amplify the subtle peak-to-valley variations in the original spectrum, making it easier to identify and analyze the spectral curve inflection points and the wavelength positions at the maximum and minimum reflectivities. [20] The low order differential of the spectrum is less sensitive to the effect of noise [21], where FD can effectively remove the influence to the sample spectrum which is caused by the partial linear or similar linear noise spectrum and background [22]. The FD equation [23]:

$$
R^{\prime}\left(\varphi_{i}\right)=\frac{R\left(\varphi_{i+1}-\varphi_{i-1}\right)}{2 \Delta \varphi}
$$

(Among, $\varphi_{i}$ was the wavelength value of each band; $R^{\prime}$ was the first derivative of the reflectance at wavelength $i ; \Delta \varphi$ was the interval of wavelength $\varphi_{i}$ to wavelength $\varphi_{i-1}$, where the larger $\Delta \varphi$ was, the smoother the spectral curve was. The value of $\Delta \varphi$ which was too large will lead to the removal of useful spectral information, which was too small will not achieve the desired effect, The value of $\Delta \varphi$ in this paper was set to 2.)

\subsection{Model Establishment and Verification}

Support Vector Machine (SVM) was used to establish the spectral model of soil nitrate nitrogen content. SVM is a new machine learning method based on statistical learning theory and structural risk minization [24]. It uses the limited sample information to find the best compromise between model complexity and learning ability and has good generalization ability. It uses the kernel function to reduce the computational complexity of mapping low-dimensional space vector into high-dimensional space, and has been successfully applied in small sample, nonlinear, high-dimensional pattern recognition and other fields [25].

The accuracy and estimation capability of the model were tested by the coefficient of determination $\left(R^{2}\right)$, the root mean square error (RMSE) and the relative analysis error (RPD). The larger $\mathrm{R}^{2}$ was, the smaller the RMSE was, the better the estimation accuracy of the prediction model was. In addition, when RPD $>2$, the model had excellent predictive ability; when $1.4<\mathrm{RPD}<2$, the model could make a rough prediction of the sample; when RPD $<1.4$, the model could not estimate the sample [26]. 


$$
\begin{aligned}
R^{2} & =\frac{\sum\left(\hat{y}_{i}-\bar{y}_{i}\right)^{2}}{\sum\left(y_{i}-\bar{y}\right)^{2}} \\
R M S E & =\sqrt{\frac{1}{n} \sum_{i=0}^{n}\left(y_{i}-\hat{y}_{i}\right)^{2}} \\
R P D & =\operatorname{STDEV}\left(y_{i}\right) / \sqrt{\frac{1}{n} \sum_{i=1}^{n}\left(\hat{y}_{i}-y_{i}\right)^{2}}
\end{aligned}
$$

(Among, $y_{i}$ was the measured value; $\hat{y}_{i}$ was the predicted value; $\bar{y}$ was the average of the measured value; $\bar{y}_{i}$ was the average value of the predicted value; $\mathrm{n}$ was the number of samples.) [27]

\section{Results}

\subsection{Spectral Characteristics of Soil Samples with Different Nitrate Nitrogen Content}

All soil samples were divided into four groups averagely according to the level of the soil nitrate nitrogen content, and then all the soil spectral curves in each group were averaged to obtain the spectral reflectance curves under different nitrate nitrogen content (Figure 2). It could be seen from Figure 2 that the variation trend of the soil spectral curves of different nitrate nitrogen content was basically similar. In the range of $400 \mathrm{~nm}$ to $2450 \mathrm{~nm}$, there were three distinct water absorption valleys $(1400 \mathrm{~nm}, 1900 \mathrm{~nm}$ and $2200 \mathrm{~nm}$ ), which may be related to the water content in the apple orchards soils [28]. In the visible range, the reflectance of soil samples was low, but the reflectance increased rapidly with the increase of the wavelength. In the near-infrared range, the spectral curve began to flatten. The spectral curve began to show an overall downward trend after $2200 \mathrm{~nm}$, which reflected the typical soil spectral characteristics. With the increase of the nitrate nitrogen content, the general reflectance of soil spectral reflectance was decreasing, which was close to the conclusion that spectral reflectance was decreasing with the increase of organic matter content in previous stu-

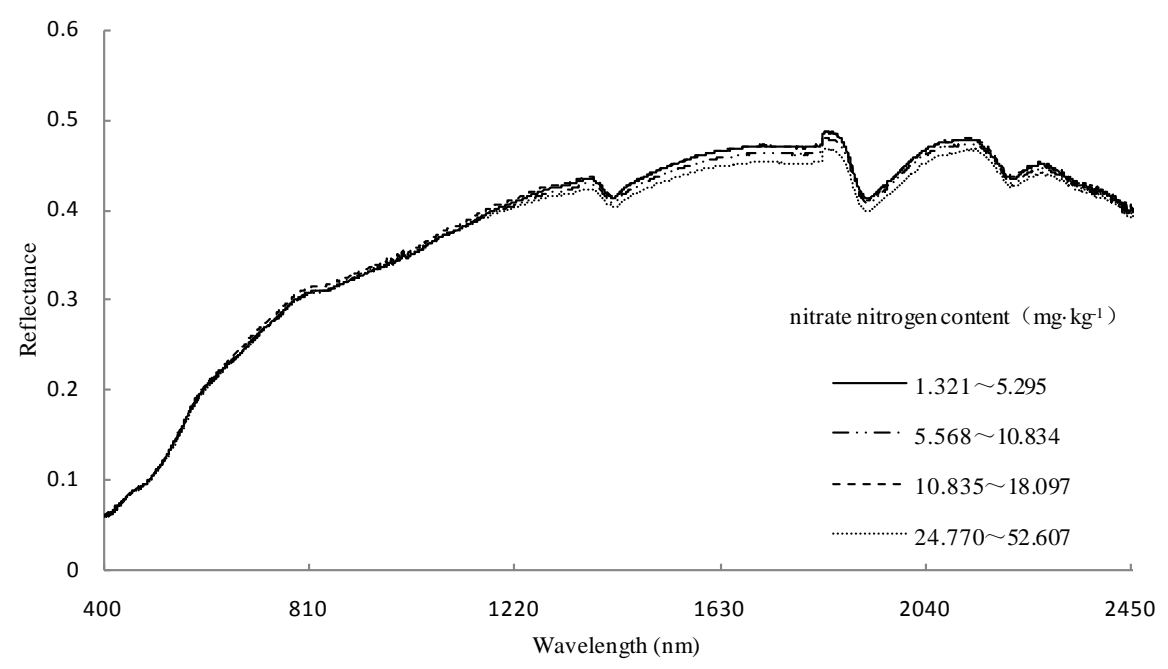

Figure 2. The spectral reflectance of soil samples with different nitrate nitrogen content. 
dies [12]. However, the spectral reflectance of the soil was abnormally high in the range of $10.835 \mathrm{mg} \cdot \mathrm{kg}^{-1}$ to $18.097 \mathrm{mg} \cdot \mathrm{kg}^{-1}$, which did not follow the general trend of decreasing, indicating that when the soil nitrate nitrogen content in this range, the spectral reflectance of the soil may be affected by other factors, thus affecting the accuracy of the nitratenitrogen spectral prediction model.

\subsection{Soil Nitrate Nitrogen Sensitive Spectral Band Selection}

Figure 3 showed the correlation between the soil nitrate nitrogen content and the original reflectance and the correlation between the soil nitrate nitrogen content and the reflectance after MSC. It could be seen from Figure 3, the coefficient after MSC had been significantly improved, eliminating the scattering effects of the uneven of particle and particle size effectively.

The FD treatment was carried out on the spectral reflectance after MSC, to obtain the correlation between the soil nitrate nitrogen and the spectral reflectance after the transformation, as shown in Figure 4. According to the maximum principle of correlation coefficient, the sensitive wavelengths of soil nitrate nitrogen were selected, which were $617 \mathrm{~nm}, 760 \mathrm{~nm}, 1239 \mathrm{~nm}, 1442 \mathrm{~nm}, 1535 \mathrm{~nm}$, $1695 \mathrm{~nm}, 1776 \mathrm{~nm}, 1907 \mathrm{~nm}$ and $2088 \mathrm{~nm}$.

\subsection{Establishment and Verification of Spectral Inversion Model for Soil Nitrate Content}

The nonlinear SVM model was established using the data after MSC combined with FD. The radial basis function (RBF) was chosen as kernel function of the SVM model, and the penalty coefficients $C$ and kernel coefficients RBF which had a great influence on the result were determined by several tests. The rest of the parameters adopted the default values. After several tests, when the $\mathrm{C}$ value was set to 10 and gamma value was set to 0.4 , the effect was the best. The $\mathrm{R}^{2}$ of the prediction set of the SVM model was as high as 0.9585 , the RMSE was 0.281,

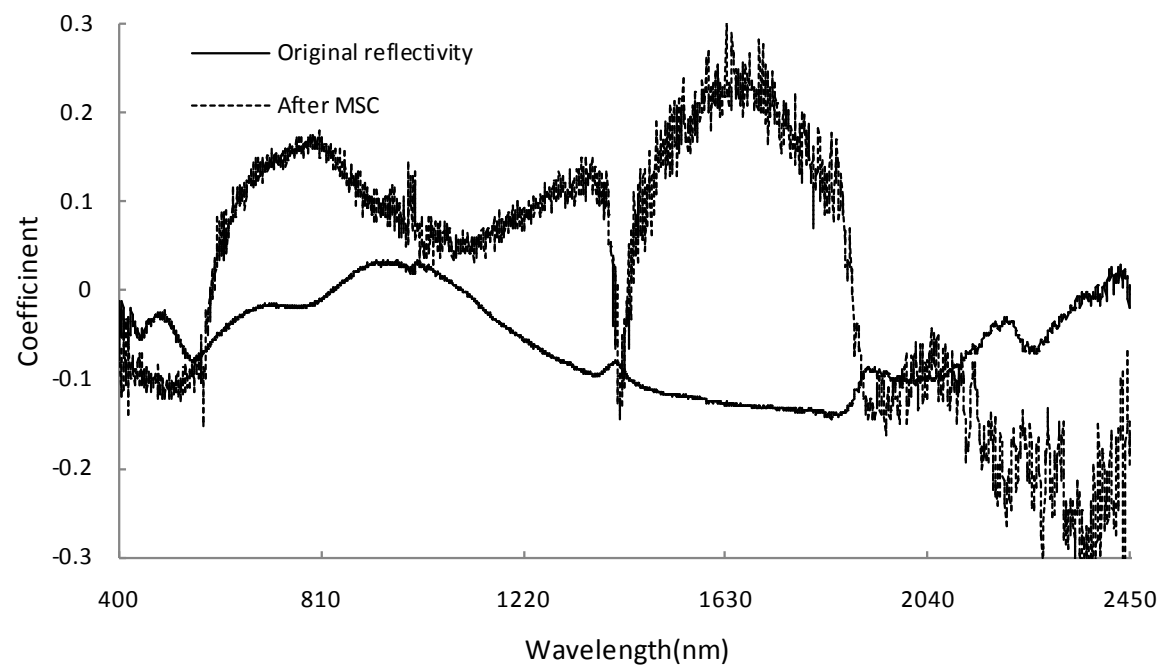

Figure 3. Correlation of soil nitrate nitrogen content with original reflectance and reflectance after MSC. 


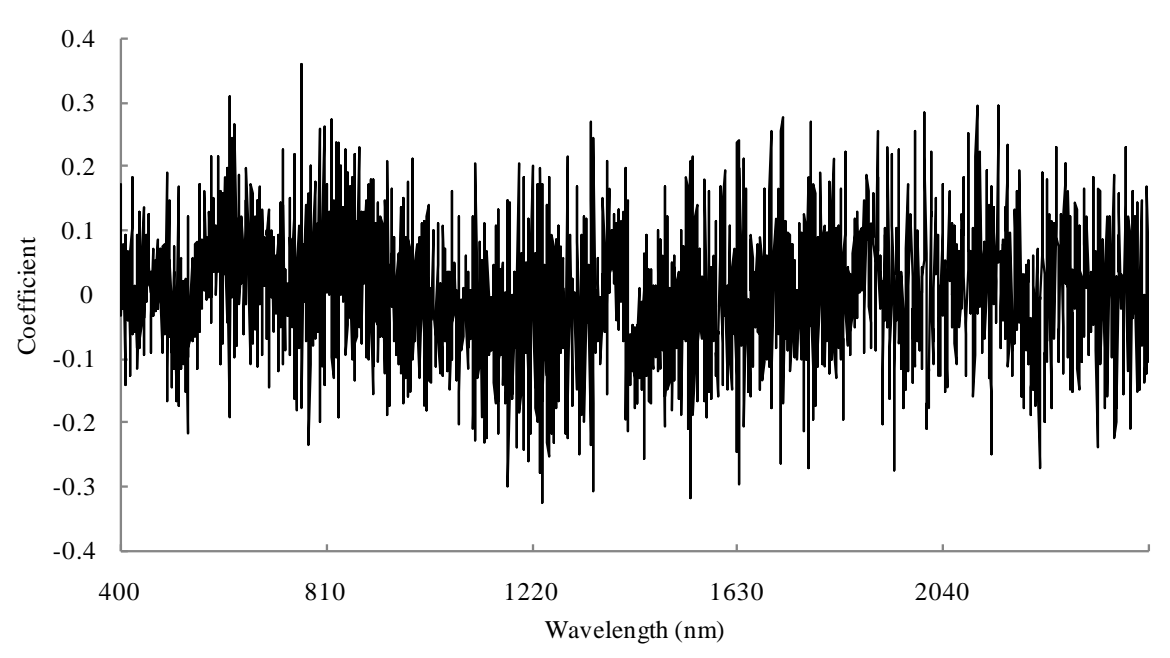

Figure 4. Correlation of soil nitrate nitrogen content with reflectance after MSC and FD.

and the RPD was 3.835 (more than 2), which indicated that the model had a good prediction accuracy.

In order to make the effect of model prediction more intuitionistic, the measured values and predicted values of the calibration set of the SVM model were plotted as a scatter plot, as shown in Figure 5.

It could be seen from Figure 5 that the $\mathrm{R}^{2}$ of the calibration set of the SVM model was 0.822 , the RMSE was 0.392 and the RPD was 2.037 , which showed that the model had good stability and reliability.

\section{Discussion}

In terms of analyzing the spectral characteristics of soil samples with different nitrate nitrogen content, the spectral reflectance of the soil was abnormally high in the range of $10.835 \mathrm{mg} \cdot \mathrm{kg}^{-1}$ to $18.097 \mathrm{mg} \cdot \mathrm{kg}^{-1}$, which did not follow the general trend of decreasing. The spectral reflectance of the soil may be influenced by other factors when the soil nitrate nitrogen content in this range, and further study was needed. In terms of selecting the sensitive wavelength, a series of sensitive wavelengths $(617 \mathrm{~nm}, 760 \mathrm{~nm}, 1239 \mathrm{~nm}, 1442 \mathrm{~nm}, 1535 \mathrm{~nm}, 1695 \mathrm{~nm}$, $1776 \mathrm{~nm}, 1907 \mathrm{~nm}, 2088 \mathrm{~nm}$ ) were selected, in which $617 \mathrm{~nm}, 760 \mathrm{~nm}, 1239 \mathrm{~nm}$, $1442 \mathrm{~nm}, 1695 \mathrm{~nm} 1776 \mathrm{~nm}$ were consistent with the best bands of predicting soil total nitrogen in the visible and near-infrared regions by the previous studies [9] [29] [30] [31]. In addition, two sensitive wavelengths of $1535 \mathrm{~nm}$ and 1907 $\mathrm{nm}$ in the near-infrared long-wave region were newly discovered, which were considered as the important wavelengths of soil nitrogen content distinguishing from soil total nitrogen. In terms of the establishment and verification of spectral inversion model for soil nitrate content, Viscarra Rossela [32] used the spectral analysis method to predict and analyze various physical and chemical parameters of the soil, in which the linear PLSR model for soil nitrate content was established with low precision. SVM is a non-linear regression model, which is more accurate than the linear model established by previous researchers. In this paper, the hyperspectral monitoring model of soil nitrogen content established by SVM 


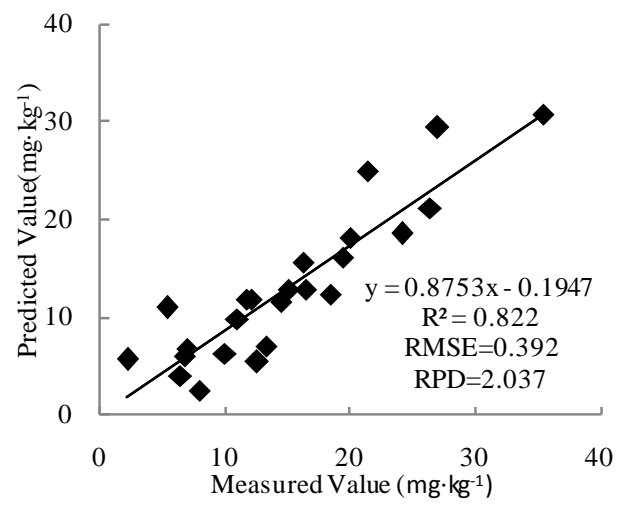

Figure 5. Comparison of predicted and measured values of soil.

had a good fitting effect. However, further study is needed when the selected penalty coefficients $\mathrm{C}$ and kernel coefficients RBF are applied to other applications. This study took the apple orchards soil in Qixia county of Shandong Province as the research object, and soil type and soil texture in different regions are different. If the monitoring model of soil nitrate nitrogen which was established is applicable to other soil types in other regions, further research is needed.

\section{Conclusion}

Using the ASD Fieldspec 3 to obtain the hyperspectral reflectance information of soil samples, a method for rapid monitoring of soil nitrate nitrogen content in the apple orchards in Qixia county was established. 72 soil samples were selected as the prediction set, a hyperspectral monitoring model by SVM could well predict the soil nitrate nitrogen content using MSC combined with FD pretreatment method, and the $\mathrm{R}^{2}$ was 0.9585 , the RMSE was 0.281 , and the RPD was 3.835 . While the $\mathrm{R}^{2}$ of the calibration set was 0.822 , the RMSE was 0.392 , and the RPD was 2.037. The results showed that the SVM model had a high accuracy in predicting soil nitrate nitrogen content.

\section{References}

[1] Li, M.Z. (2001) Spectral Analysis Technology and Its Application. Science Press, Beijing.

[2] Chang, C.W., Laird, D.A., Mausbach, M.J. and Hurburgh Jr., C.R. (2001) NearInfrared Reflectance Spectroscopy-Principal, Components Regression Analyses of Soil Properties. Soil Science Society of America Journal, 65, 480-490. https://doi.org/10.2136/sssaj2001.652480x

[3] Confalonieri, M., Fornasier, F., Ursino, A., Boccardi, F. and Pintus, B (2001) The Potential of Near Infrared Reflectance Spectroscopy as a Tool for the Chemical Characterization of Agricultural Soils. Journal of Near Infrared Spectroscope, 123-131. https://doi.org/10.1255/jnirs.299

[4] Lee, K.S., Lee, D.H., Sudduth, K.A., Chung, S.O., Kitchen, N.R. and Drummond, S.T. (2009) Wavelength Identification and Diffuse Reflectance Estimation for Surface and Profile Soil Properties. American Society of Agricultural and Biological Engineers, 52, 683-695. 
[5] Genot, V., Colinet, G., Bock, L., Dominique, V., Reuren, Y. and Dardenne, P. (2011) Near infrared Spectroscopy for Estimating soil Characteristics Valuable Reflectance in the Diagnose of Sail Fertility. Journal of Nearlnfrared Spectroscope, 19, 117-138.

[6] Yu, F.J., Min, S.G., Ju, X.T. and Zhang, F.S. (2002) Determination the Content of Nitrogen and Organic Substance in Dry Soil by Using Near Infrared Diffusion Reflectance Spectroscopy. Chinese Journal of Analysis Laboratory, 1, 49-51.

[7] Lu, Y.L., Bai, Y.L., Wang, L., Wang, H. and Yang, L.P. (2010) Determination for Total Nitrogen Content in Black Soil Using Hyperspectral Data. Ransactions of the CSAE, 26, 256-261.

[8] Zhang, J.J., Tian, Y.C., Yao, X., Cao, W.X., Ma, X.M. and Zhu, Y. (2011) Estimating Soil Total Nitrogen Content Based on Hyperspectral Analysis Technology. Journal of Natural Resources, 26, 881-890.

[9] Peng, J., Xiang, H.Y., Zhou, Q., Wang, J.Q., Liu, W.Y., Chi, C.M. and Pang, X.A. (2013) Prediction on Total Nitrogen Content in Different Type Soils Based on Hyperspectrum. Chinese Agricultural Science Bulletin, 29, 105-111.

[10] Yang, C., Xing, Y.C. and Li, J.M. (2001) Near Infrared Spectroscopy Determination of Soil Total Nitrogen Based on OSC. Forest Engineering, 29, 25-28.

[11] Viscarra Rossel, R.A. and Behrens, T. (2010) Using Data Mining to Model and Interpret Soil Diffuse Reflectance Spectra. Geoderma, 158, 46-54.

https://doi.org/10.1016/j.geoderma.2009.12.025

[12] Ji, W.J., Li, X., Li, C.X., Zhou, Y. and Shi, Z. (2012) Using Different Data Mining Algorithms to Predict Soil Organic Matter Based on Visible-Near Infrared Spectroscopy. Spectroscopy and Spectral Analysis, 32, 2393-2398.

[13] Han, Z.Y., Zhu, X.C., Liu, Q., Fang, X.Y. and Wang, Z.Y. (2014) Hyperspectral Inversion Models for Soil Organic Matter Content in the Yellow River Delta. Journal of Plant Nutrition and Fertilizer, 20, 1545-1552.

[14] Zhu, X.C., Zhao, G.X., Dong, F., Wang, L., Wang, L., Lei, T. and Zhan, B. (2009) Monitoring Models for Phosphorus Content of Apple Flowers Based on Hyperspectrum. Chinese Journal of Applied Ecology, 20, 2424-2430.

[15] Wang, L.N., Zhu, X.C., Liu, Q., Zhao, G.X., Li, H.Y., Wang, L. and Zhang, S.W. (2013) Hypersperpectral Quantitative Estimation of Saline-Alkali Soil Salinity in the Yellow River Delta. Chinese Journal of Soil Science, 44, 1101-1106.

[16] Song, G., Sun, B. and Jiao, J.Y. (2007) Comparison between Ultraviolet Spectrophotometry and Other Methods in Determination of Soil Nitraten. Acta Pedologica Sinica, 44, 288-293.

[17] Isaksson, T. and Naes, T. (1988) The Effect of Multiplicative Scatter Correction and Linearity Improvement on NIR Spectroscop. Applied Spectroscopy, 42, 1273-1284. https://doi.org/10.1366/0003702884429869

[18] Shen, Y., Zhang, X.P., Liang, A.Z., Shi, X.H., Fan, R.Q. and Yang, X.M. (2010) Multiplicative Scatter Correction and Stepwise Regression to Build NIRS Model for Analysis of Soil Organic Carbon Content in Black Soil. System Sciences and Comprehensive Studies in Agriculture, 26, 174-180.

[19] Chu, X.L., Yuan, H.F. and Lu, W.Z. (2004) Progress and Application of Spectral Data Pretreatment and Wavelength Selection Methods in NIR Analytical Technique. Progress in Chemistry, 16, 528-542.

[20] He, T., Wang, J., Lin, Z.J. and Cheng, Y. (2006) Spectral Features of Soil Organic Matter. Geomatics and Information Science of Wuhan University, 31, 975-979.

[21] Pu, R.L. and Gong, P. (2000) Hyperspectral Remote Sensing and Application. Higher Education Press, Beijing, Vol. 8, 3-4. 
[22] Cloutis, E.A. (1996) Hyperspectral Remote Sensing: Evaluation of Analytical Techniques. Journal of Remote Sensing, 17, 2215-2242. https://doi.org/10.1080/01431169608948770

[23] Zheng, Y.M., Zhang, T.Q., Zhang, J., Chen, X.D. and Shen, X.G. (2004) Influence of Smooth. 1st Derivative and Baseline Correction on the Near-Infrared Spectrum Analysis with PLS. Spectroscopy and Spectral Analysis, 24, 1546-1548.

[24] Liu, Y.Q., Chen, H.Y., Wang, R.Y., Chang, C.Y. and Chen, Z. (2016) Quantitative Analysis of Soil Salt and Its Main Ions Based on Visible/Near Infrared Spectroscopy in Estuary Area of Yellow River. Scientia Agricultura Sinica, 49, 1925-1935.

[25] Zhang, S., Shi, W.R., Shi, X. and Guo, B.L. (2015) Water Quality Prediction Based on Partial Least Squares and Support Vector Machine. Computer Engineering and Applications, 51, 249-254.

[26] Krishnan, P., Alexander, J.D., Butler, B.J. and Hummel, J.W. (1980) Reflectance Technique for Predicting Soil Organic Matter. Soil Science Society of America Journal, 44, 1282-1285. https://doi.org/10.2136/sssaj1980.03615995004400060030x

[27] Gao, L.M. (2014) Monitoring the Soil Nitrogen and Soil Moisture in Winter Wheat Field Based on the Hyperspectral Technology. Master's Thesis, Shanxi Agricultural University, Taigu.

[28] Huang, Y.F. and Liu, T.H. (1995) Spectral Characteristics of Main Types of Soil in Southern China and Soil Classification. Acta Pedologica Sinica, 32, 58-68.

[29] Wu, M.Z., Li, X.M. and Sha, J.M. (2013) Spectral Inversion Models for Prediction of Red Soil Total Nitrogen Content in Subtropical Region. Spectroscopy and Spectral Analysis, 33, 3111-3115.

[30] Krishnan, P., Alexander, J.D., Butler, B.J. and Hummel, J.W. (1980) Reflectance Technique for Predicting Soil Organic Matter. Soil Science Society of America Journal, 44, 1282-1285. https://doi.org/10.2136/sssaj1980.03615995004400060030x

[31] Lee, W.S., Sanchez, J.F., Mylavarapu, R.S. and Choe, J.S. (2003) Estimating Chemical Properties of Florida Soil Using Spectral Reflectance. Transactions of the ASAE, 46, 1443-1453.

[32] ViscarraRossela, R.A., Walvoort, D.J.J., McBratney, A.B., Janik, L.J. and Skjemstad, J.O. (2006) Visible, Near Infrared, Mid Infrared or Combined Diffuse Reflectance Spectroscopy for Simultaneous Assessment of Various Soil Properties. Geoderma, 131, 59-75. https://doi.org/10.1016/j.geoderma.2005.03.007

\section{Submit or recommend next manuscript to SCIRP and we will provide best service for you:}

Accepting pre-submission inquiries through Email, Facebook, LinkedIn, Twitter, etc. A wide selection of journals (inclusive of 9 subjects, more than 200 journals)

Providing 24-hour high-quality service

User-friendly online submission system

Fair and swift peer-review system

Efficient typesetting and proofreading procedure

Display of the result of downloads and visits, as well as the number of cited articles

Maximum dissemination of your research work

Submit your manuscript at: http://papersubmission.scirp.org/

Orcontact as@scirp.org 